\title{
Parental Attitudes to Myopia: a Key Agent of Change for Myopia Control?
}

\author{
Saoirse McCrann \\ Technological University Dublin, c08375054@mydit.ie \\ Ian Flitcroft \\ Children's University Hospital, Dublin \\ Kevin Lalor \\ Technological University Dublin, kevin.lalor@tudublin.ie
}

See next page for additional authors

Follow this and additional works at: https://arrow.tudublin.ie/scschphyart

Part of the Optometry Commons

\section{Recommended Citation}

McCrann, S. et al. (2018) Parental attitudes to myopia: a key agent of change for myopia control?Ophthalmic Physiol Opt 2018; 38: 298-308. https://doi.org/10.1111/opo.12455

This Article is brought to you for free and open access by the School of Physics \& Clinical \& Optometric Science at ARROW@TU Dublin. It has been accepted for inclusion in Articles by an authorized administrator of ARROW@TU Dublin. For more information, please contact arrow.admin@tudublin.ie, aisling.coyne@tudublin.ie, gerard.connolly@tudublin.ie.

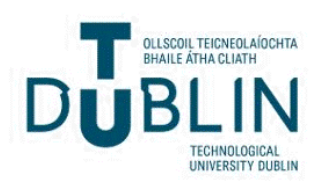


Authors

Saoirse McCrann, Ian Flitcroft, Kevin Lalor, John Butler, Aaron Bush, and James Loughman

This article is available at ARROW@TU Dublin: https://arrow.tudublin.ie/scschphyart/78 


\section{Title}

Parental attitudes to myopia: A key agent of change for myopia control?

\section{Running head}

Parental attitudes to myopia

Lead Author

Saoirse McCrann ${ }^{1}$

Co-Authors

Prof. Ian Flitcroft ${ }^{1,2}$

Dr. Kevin Lalor ${ }^{3}$

Dr. John Butler ${ }^{4}$

Mr. Aaron Bush ${ }^{5}$

Prof. James Loughman ${ }^{1,6}$

${ }^{1}$ School of Physics and Clinical and Optometric Sciences, Dublin Institute of Technology, Dublin, Ireland

${ }^{2}$ Childrens University Hospital, Dublin, Ireland

${ }^{3}$ School of Languages, Law and Social Sciences, Dublin Institute of Technology, Dublin, Ireland

${ }^{4}$ School of Mathematical Sciences, Dublin Institute of Technology, Dublin, Ireland

${ }^{5}$ Lincoln Memorial University-DeBusk College of Osteopathic Medicine, Harrogate, Tennessee

${ }^{6}$ African Vision Research Institute, University of KwaZulu Natal, Durban, South Africa

Correspondence: Saoirse McCrann

E-mail address: mccrannsaoirse@gmail.com 
Disclosure: The authors report no conflicts of interest and have no proprietary interest in any of the materials mentioned in this article

\section{Acknowledgements:}

The authors thank the schools who participated in the study: Scoil Mhuire Gan Smál, Ballinlig National School, Scoil Asicus, Carraroe National School, St. Teresa's National School, Scoil Na Mainistreach, St Canices Girls National School, Dublin and St.Fiachra's Junior National School, Dublin

Keywords: myopia, myopia control, parental attitudes, lifestyle habits, risk factors, environment and myopia 


\section{$\underline{\text { Abstract }}$}

Purpose

With the increasing prevalence in myopia there is growing interest in active myopia prevention. This study aims to increase our understanding of parental attitudes to myopia development and control, as a means to inform future health planning and policy. It evaluates, for the first time, the attitude of parents to myopia and its associated risks, as well as assessing the exposure of Irish children to environmental factors that may influence their risk profile for myopia development.

\section{Methods}

Parents of 8-13 year old children in eight participating schools completed a questionnaire designed to assess their knowledge of and attitudes towards myopia and its risk factors. A structured diary was also used to capture daily activities of children in relation to myopia risk factors.

\section{Results}

Of 329 parents, just $46 \%$ considered that myopia presented a health risk to their children, while an identical number (46\%) regarded it as an optical inconvenience. Myopia was also, but less frequently, considered an expense ( $31 \%$ of parents), a cosmetic inconvenience (14\% of parents) and, by some, as a sign of intelligence ( $4 \%$ of parents)

$76 \%$ of parents recognised the potential of digital technology to impact the eye, particularly as a cause of eyestrain and need for spectacles. Only $14 \%$ of parents expressed concern should their child be diagnosed with myopia.

Compared to non myopic parents, myopic parents viewed myopia as more of an optical inconvenience $(P<0.001)$, an expense $(P<0.005)$ and a cosmetic inconvenience $(P<0.001)$. There was a trend for myopic parents to limit screen time use in their household more than non-myopic parents $(P=0.05)$. Parents who considered myopia a health risk sought to limit screen time more than parents who did not regard myopia as a health risk to their child $(P=0.01)$. Children spent significantly longer performing indoor proximal tasks (255 mins) compared to time spent outdoors $(180 \mathrm{mins})(P<0.0001)$ daily. Older $(P=0.001)$, urban $(P=0.0005)$ myopic $(=0.04)$ children spent significantly more time at digital screens compared to younger non-myopic children from a rural background.

\section{Conclusion}

Parental attitudes to myopia were typically nonchalant in relation to health risk. This is of particular concern given the impact parents have on children's behaviour and choices with respect to such risk factors, demonstrating an acute need for societal sensitisation to the public health importance of myopia. 


\section{Introduction}

Myopia is predicted to affect a staggering 2.5 billion people worldwide by $2020,{ }^{1}$ and is set to double again to almost 5 billion by $2050 .^{2}$ In East and Southeast Asia, the prevalence of myopia has doubled in the past 30 years. ${ }^{3}$ Similar extraordinary increases in prevalence have affected Western society, with myopia prevalence doubling over a similar time period to almost $50 \%$ among school-leavers in the USA, ${ }^{4}$ and over 50\% in parts of Europe, ${ }^{5}$ including the UK. ${ }^{6}$ Children are becoming more myopic at a younger age, ${ }^{7,8}$ with the degree of myopia continuing to increase in magnitude over time. ${ }^{9,10}$

The public health implications of a continued increase in myopia prevalence and magnitude include a range of adverse societal, economic, educational and quality of life impacts. Epidemiological studies indicate that myopia is second only to age as a risk factor for many of the major eye diseases (glaucoma/cataract/retinal detachment), ${ }^{11}$ and is the primary risk factor in myopic maculopathy. ${ }^{12}$ The increasing prevalence and magnitude of myopia is associated with a dose-dependent increased risk of such conditions, and is therefore, already adversely influencing societal vulnerability to eye disease..$^{8,11}$ Myopic maculopathy is a leading cause of blindness in Asia ${ }^{14}$ and has been consistently shown as a major cause of blindness among the working age population across Europe. ${ }^{15,16,17,18,19}$ Should the myopia pandemic continue unabated, current estimates indicate that a seven-fold increase in the number of people who will suffer vision loss and blindness is possible from 2000 to $2050 .^{2}$ The above concerns all point to the urgent need for targeted interventions that (a) reduce the risk of developing myopia in the first instance and (b) slow or halt the progression of myopia once diagnosed.

While the causes of myopia are both genetic and environmental, the recent and precipitous changes in myopia prevalence are thought to primarily reflect changing environmental influences. ${ }^{20}$ In Singapore, both the prevalence and degree of myopia correlate with the time spent in full time education. ${ }^{21}$ In Inuit populations with little genetic heterogeneity, the incidence of myopia has rapidly increased in line with acculturation and formal schooling over as few as two generations. ${ }^{20,22}$ Jewish Orthodox male students in intense schooling involving sustained near vision were more likely to be myopic than girls from the same families who had a more normal educational upbringing. ${ }^{23}$ Studies have also demonstrated positive associations between myopia and continuous reading or longer periods of close work, ${ }^{24,25}$ and with reading more books per week. ${ }^{26}$ Likewise it has been postulated that the increased use of personal electronic devices, continuous hours at a screen or the proximity of the screen to the face may influence myopic refractive error, even though myopia was a significant issue and was rising prior to the widespread adoption of smart phones or tablets. However the rapid and widespread adoption of such technology certainly merits research into its possible impact on visual development in children. 
Recent studies have, therefore, focused on investigating myopia development and technology usage, ${ }^{27,28,}$ ${ }^{29}$ particularly computer and mobile phone usage, which have evolved rapidly over the past ten years, ${ }^{30}$ with electronic visual display technology now at the forefront in many schools and workplaces. Today's children are growing up in a world saturated with technology that demands proximal attention and competes for the leisure time available to children, with the average American youth now spending onethird of each day engaged in some form of electronic media. ${ }^{31}$ Although not all studies are consistent in demonstrating a near-work myopia relationship, ${ }^{25}$ it is conceivable that extensive exposure to screens might represent a risk factor for the development or progression of myopia and may have contributed to the recent rapid rise in the prevalence of myopia, especially in younger age cohorts.

This increased risk may relate to increased levels of proximal attention, altered patterns of near work such as the very short viewing distances associated with mobile phones, adverse influences on time spent outdoors or some combination of each of these factors. These potential contributions have yet to be fully elucidated and it is, therefore, essential to understand the influence of our contemporary environment on myopia onset and progression.

Time spent outdoors is also considered an important factor in relation to risk of incident myopia. ${ }^{32,33,34,35}$ Modern society's increased emphasis on education, ${ }^{36}$ the lack of green spaces due to urbanisation ${ }^{2}$ and the extensive use of technology and smart devices ${ }^{37}$ are all thought to detract from quality time spent outdoors, and comprise key drivers of this unprecedented myopia boom.

Although there is no established "cure" for myopia, there is now a growing body of evidence demonstrating that myopia risk can be managed and myopia progression controlled. Interventions to increase time spent outdoors have, for example, proven to be effective in terms of reducing the risk of myopia development. ${ }^{38,39}$ A range of optical and pharmacological treatments have now been shown to have the capacity to significantly reduce myopia progression, both in terms of refraction and axial growth. ${ }^{40}$ Despite this evidence, very few practitioners are actively offering such treatment. ${ }^{41}$ Slow acceptance that myopia is a treatable condition ${ }^{42}$, concerns about the safety, cost and the availability of myopia control interventions are perceived barriers to myopia control practice. ${ }^{41}$ The lack of uptake of available treatment options by practitioners confirms the need for stakeholder sensitisation regarding public health policy and clinical practice reform for myopia control.

There is a scarcity of published literature that probes the attitudes of individuals to myopia and its control. A structured search of MEDLINE, EMBASE, Google Scholar, Scopus, the World Health Organization International Clinical Trials Registry Platform, and ClinicalTrials.gov databases during the preparatory stages of this study revealed only two research papers and one survey that explored the awareness and 
attitudes of stakeholders toward myopia and myopia control. The limited research that exists, however, suggests that there is a lack of understanding of myopia, its risk factors and myopia control techniques among eye care practitioners, parents, teachers and students. ${ }^{43,41,44}$ The importance of creating awareness around the causes of myopia and benefits of myopia control cannot be underestimated. ${ }^{45}$ Parents can play an integral role given their particular influence on the lifestyle choices of children. The success of any strategy that requires behavioural modification or acceptance of new treatment regimens for children will likely depend on parental awareness of the condition and on their acceptance of the proposed interventions as a necessary treatment option.

From a myopia perspective, there are interesting parallels to be drawn to the emergent problem of childhood obesity. Obesity reflects a condition whose cause is rooted in a rapidly evolving pattern of lifestyle choices and environmental risk exposures. Health policy for childhood obesity management reflects the concept that childhood obesity "needs to be tackled where it starts -at home" ${ }^{46}$ The most effective interventions are those which target parents as key mediators of change in child eating and physical activity behaviours. ${ }^{47}$ Such family-based approaches recognise parents as integral targets of the intervention and include strategies to influence various aspects of parenting, including the environments to which children are exposed, parenting styles and practices and how child behaviour can mirror parental habits, ${ }^{48}$ all of which would seem just as critical in relation to future myopia risk management strategies. ${ }^{49}$ Promoting awareness of myopia, its causes and treatment options will help to motivate parents (and all other stakeholders) to actively prevent and treat myopia rather than just to passively alleviate the symptoms it creates.

This prospective study aims, therefore, to increase our understanding of the importance of the parental role in myopia development and control as a means to inform future health planning and policy. It evaluates, for the first time, the attitude of parents to myopia and its associated risks, as well as assessing the exposure of Irish children to environmental factors that may influence their risk profile for myopia development.

\section{$\underline{\text { Methods }}$}

1,190 school children aged between 8-13 years were invited to participate in the study. This included students from three urban and five rural schools in the Republic of Ireland, contacted through the study investigator and the Dublin Institute of Technology Access and Civic Engagement Office. Involvement in the study required completion of three key tasks; a parental questionnaire, a student daily activities diary, and a parental diary of child activities. Information regarding parental and children's refraction was 
obtained as part of the parental questionnaire. A talk was delivered to each class informing children and teachers about the research, and any questions were answered. All eligible students were then provided with an information leaflet, copies of the structured questionnaire and activity diaries and invited to discuss participation in the study with their parents. Questionnaires, diaries and consent forms were collected by the study investigator one week after distribution. Schools were contacted the day before the study investigator's return, to remind students to return their surveys.

An initial draft questionnaire for parents was constructed and subsequently analysed by an external reviewer with expertise in questionnaire design. The questionnaire was evaluated and optimised to ensure question construction did not contain leading, confusing or double-barrelled questions. The questionnaire contained 15 questions. This included three open-ended questions with a free-text box for parents to express their opinions in relation to myopia, their understanding of the consequences of myopia and their thoughts on the potential impact of technological devices on their child's eyes. Tick-box questions were used to explore parent's perceptions of myopia (e.g. as a health risk versus as an expense), and parents could tick all that applied to them. Tick box questions were also used to determine whether parents limited their child's screen usage, to record the type of outdoor activities, the child's ethnicity and whether the parents and/or child wore glasses for myopia. Both parents' and child's spectacle prescriptions (if any) were requested, as well as the age the child was first prescribed glasses, where relevant. If the parent had laser refractive surgery, the pre-surgery prescription was obtained where possible.

Parent and child diaries were designed to quantify the amount of time spent participating in activities that can influence myopic refractive error, based on previous literature. ${ }^{24,3,39}$ Participating children were tasked to complete the structured diary each night for one week to quantify time spent each day reading, writing, watching television, doing their homework, on screens (phone/computer/tablet) and playing video games. The amount of time spent outside and the type of outdoor activity was recorded. Children also documented their time of sleep and wakening for one week. Parents were required to maintain a similar record of child activity, and document the average amount of time per weekday and weekend day their child spent outdoors, on screens, reading, writing and performing other near tasks such as artwork or reading music. Parents and children were instructed to complete their respective diaries independently of each other. To prevent shared views from within a family only one parent and child from each family were invited to participate in the study.

Diaries and questionnaires were anonymous; participants were assured that all individual results would be kept strictly confidential. Participation in the study was voluntary. A passive consent form, which 
required parents to sign and return the form if they did not wish their child to participate, ${ }^{50}$ was distributed with the questionnaire for parents. The study was approved by the Research Ethics Committee at Dublin Institute of Technology. All data was collected in early Summer (May) of 2016. The data collected was analysed on the statistical package for social sciences (IBM SPSS Statistics for Windows, Version 22.0 Armonk, NY: IBM Corp.) and R version 3.2.2.in RStudio (RStudio Team (2015). RStudio: Integrated Development for R. RStudio, Inc., Boston, MA URL http://www.rstudio.com/). The KolmogorovSmirnov Test for normality determined the data we analysed was not normally distributed. Nonparametric tests were used where appropriate and the median and confidence intervals were reported throughout. A log transformation was also used to normalise certain data to facilitate further parametric analysis. The results were analysed using descriptive statistics and inferential statistics including a threeway ANOVA (using log transformed data), Mann-Whitney U test and chi-square tests of independence. A statistical significance level of $\mathrm{p}<0.05$ was adopted throughout the analysis.

\section{$\underline{\text { Results }}$}

\section{Demographics}

Eight primary schools were approached and agreed to facilitate the conduct of the study, including five rural and three urban based schools. Rural was defined as settlements with a total population of 4,000 or less. All rural schools were mixed gender schools. Urban schools consisted of 1 mixed gender school, 1 all-boys school and 1 all-girls school. Details pertaining to the flow of participants in the study are detailed in Figure 1. In all, 361 families participated in the study, although there was some minor loss of data on specific questions due to incomplete response. These included 246 urban and 114 rural based participants.

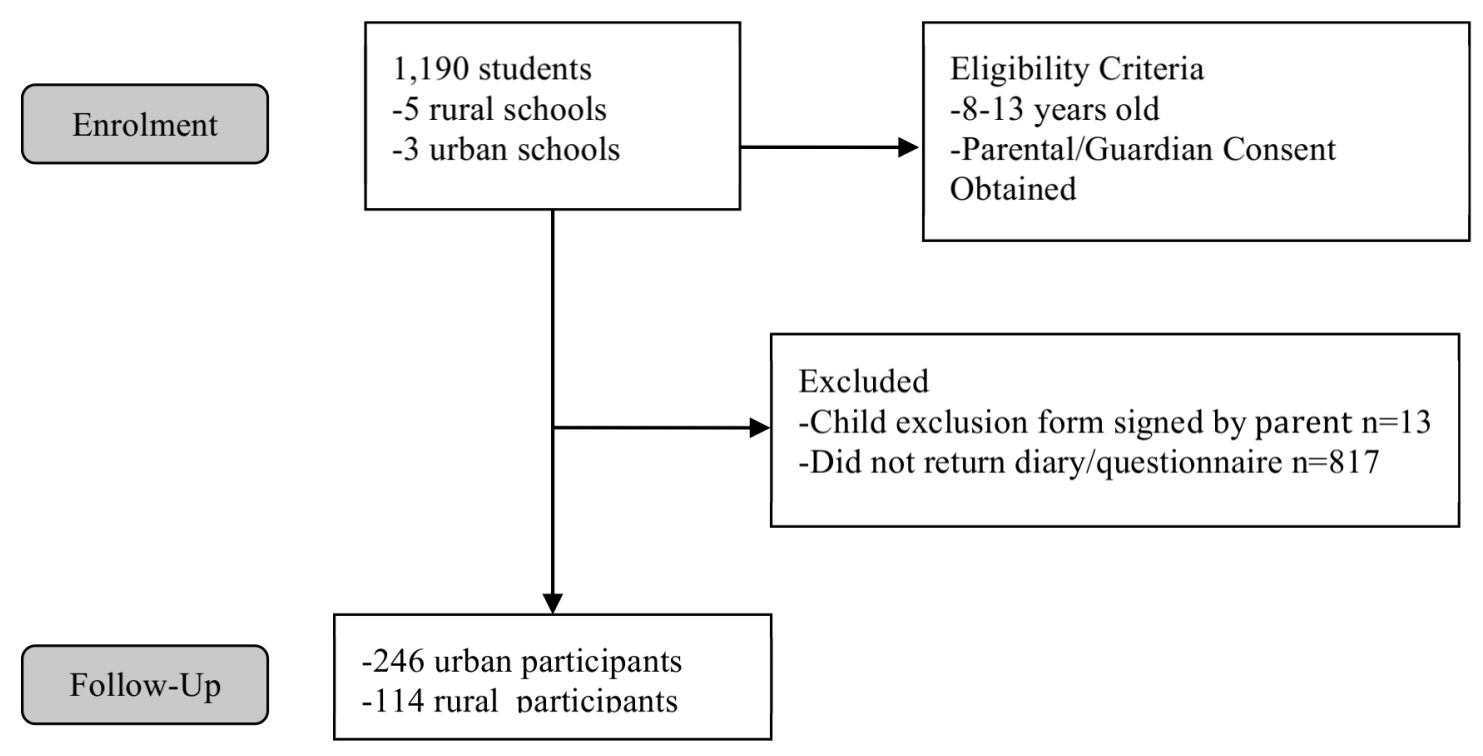


Figure 1: Flow of participants through the study

185 children were in fifth and sixth class (11-13 year olds) and 143 children were third and fourth class students (8-10 year olds). 45 children who participated in the study were myopic according to parental responses and prescriptions provided. The remainder of the children were either emmetropic or hyperopic or had undiagnosed refractive error (which may have included some undiagnosed myopes). The age (median) at which myopic participants were first prescribed glasses was 7 years, 95\% CI [4, 10]. The median myopic prescription was $-2.75 \mathrm{D}, 95 \% \mathrm{CI}[-0.25,-5.25]$ in the right eye and $-3.00 \mathrm{D}, 95 \% \mathrm{CI}[-$ $0.50,-5.50]$ in the left eye. Of the 45 myopic children, 25 were from an urban setting and the remaining 20 were attending a school in a rural area. 14 myopes were from the 8-10 year old age group and 31 of the myopic children were from the older 11-13 year old cohort. Table 1 outlines baseline characteristics of the study population.

\section{Table 1: Participant Baseline Characteristics}

\begin{tabular}{l|l|l|l}
\hline Age & Location & Myopic Parent & Myopic Child \\
8-10 years n=143 & Urban n=246 & One Parent $n=126$ & Yes $n=45$ \\
11-13 years n=185 & Rural n=114 & Both Parents n=41 & No $n=306$ \\
Missing n=33 & Missing n=1 & Missing $n=19$ & Missing $n=10$
\end{tabular}

\section{Parental Attitudes to Myopia}

Of 329 parents, just $46 \%$ considered that myopia presented a health risk to their children, while an identical number (46\%) regarded it as an optical inconvenience that could be corrected with glasses, contact lenses or laser refractive surgery. Myopia was also, but less frequently, considered aan expense (31\% of parents) a cosmetic inconvenience (14\% of parents) and, by some, as a sign of intelligence ( $4 \%$ of parents) (see Figure 2). Parents who considered myopia a health risk sought to limit screen time more than parents who did not regard myopia as a health risk to their child $\chi^{2}(2, \mathrm{~N}=324)=9.56, P=0.01$. However, a Mann- Whitney test indicated there were no significant difference in child lifestyle habits between children whose parents considered myopia a health risk compared to parents who did not 
consider myopia a health risk to their child (reading/writing $U=9106 P=0.32$, screen time $U=9987$ $\mathrm{P}=0.12$, proximal indoor activities $\mathrm{U}=11229 P=0.39$ outdoors $\mathrm{U}=11665 P=0.34$ ).
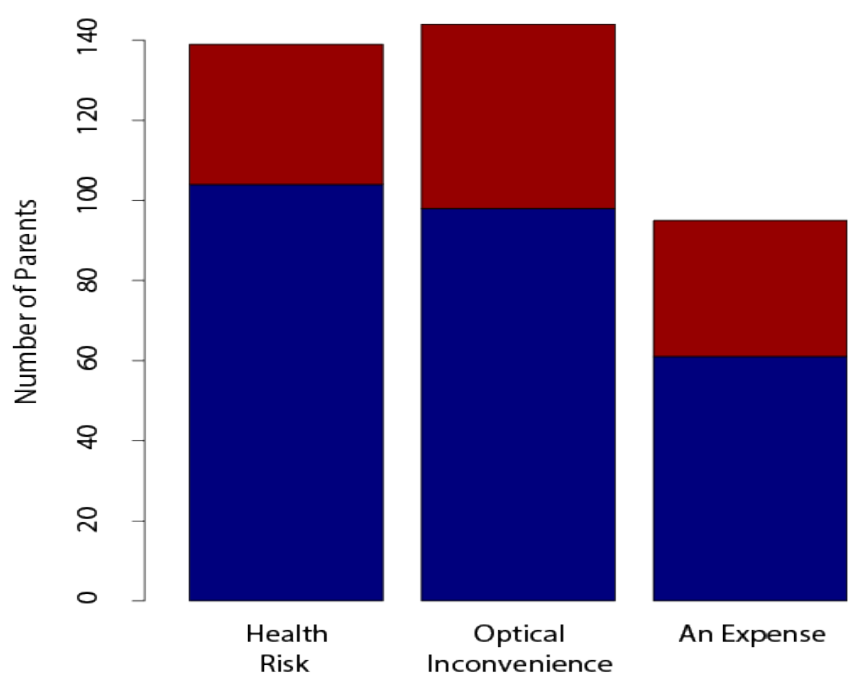

An Expense

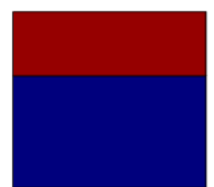

Cosmetic Inconvenience

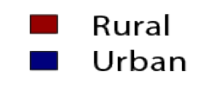

Urban

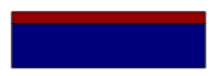

Sign of

Intelligence

Figure 2: Parental opinion of myopia as identified in tick box responses to the question "Do you see shortsightednes as: (tick all that apply)".

Only $14 \%$ of parents (52/361) expressed concern should their child be diagnosed with myopia, 63 parents had no concern should their child require spectacles, 27 parents said glasses would be an inconvenience but not a concern, 21 parents had not thought of myopia affecting their child and 9 parents thought their child was myopic but have never brought them to have an eye examination. The remaining parents did not specify their thoughts on myopia (see Figure 3). 


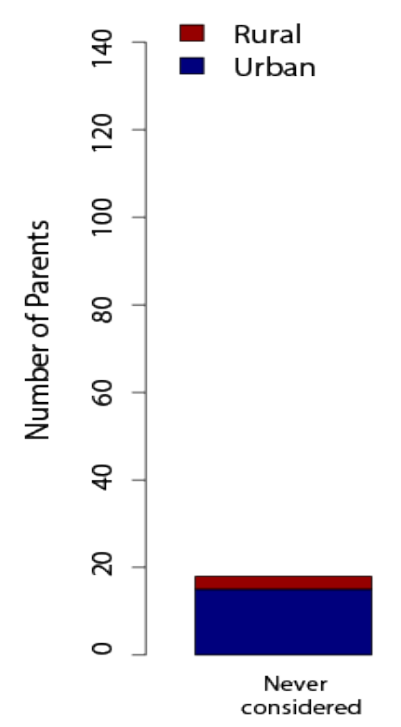

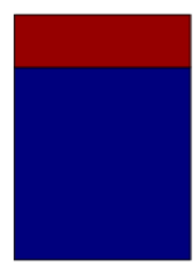

No Concern

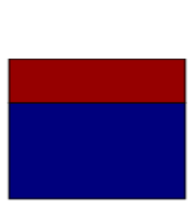

Inconvenience not a concern

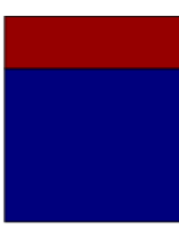

Concern

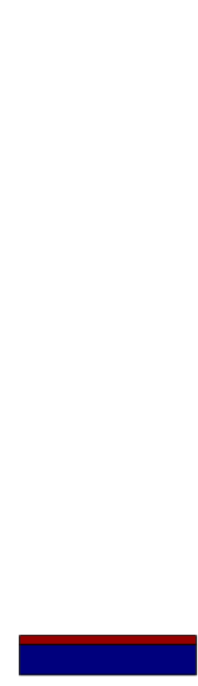

Undiagnosed myopia

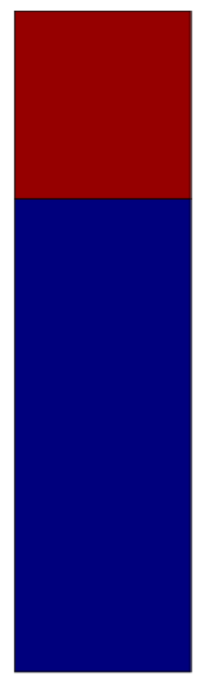

Not specified

Figure 3: Parental free text responses to the question "What do you think about the possibility that your child is, or may become, short-sighted?"

Despite the finding that most parents did not consider myopia as a health risk, a large majority of parents (76\%) did recognise the potential of digital technology to impact the eye, particularly as a cause of eyestrain and need for spectacles (see Figure 4). Most parents (78\%) indicated that they sought to limit time using screens. Yet only 18 of 327 parents recognised any long-term risk from increased use of technology. Parents considered genetic predisposition and the use of technology as the two main causal factors for myopia. 


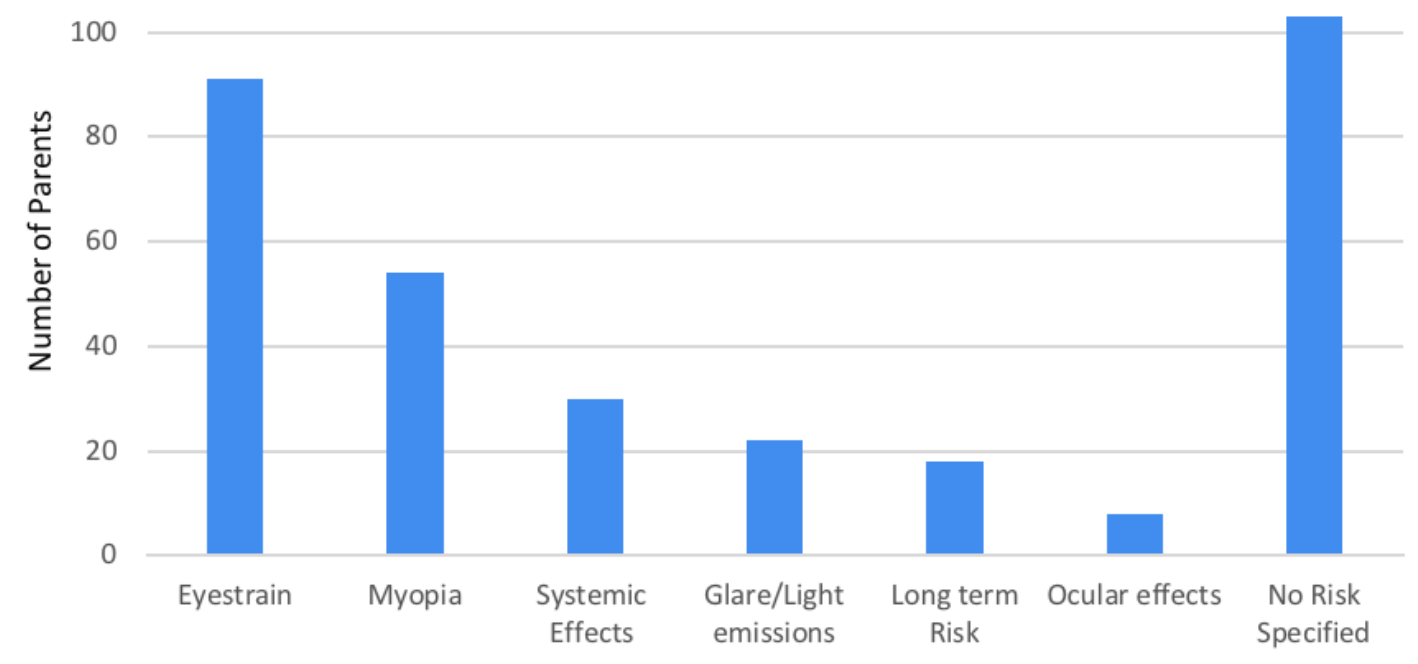

Parent Identified Risks of Screen Overuse

Figure 4: Ocular risks identified by parents in free-text responses to the question "what do you think are the potential risks/effects (of digital technology) on the eyes".

\section{Relationship between attitudes and family myopia status}

A chi-square test of independence was performed to examine the relationship between family myopia status and attitudes toward myopia. Compared to non-myopic parents, myopic parents viewed myopia as more of an optical inconvenience $\chi^{2}(2, \mathrm{~N}=308)=16.08, P=0.0003$ (Figure 5 left), an expense $\chi^{2}(2, \mathrm{~N}$ $=308)=11.91, P=0.0025$ (Figure 5 middle) and a cosmetic inconvenience $\chi^{2}(2, \mathrm{~N}=308)=20.51$, $P<0.0001$ (Figure 5 right). Myopic parents limited screen time use in their household more than nonmyopic parents, although this result was borderline significant $\chi^{2}(2, \mathrm{~N}=303)=5.95, P=0.05$. There was no significant difference in perceptions of health risk associated with myopia between myopic and nonmyopic parents $\chi^{2}(2, \mathrm{~N}=308)=4.04, P=0.13$. 


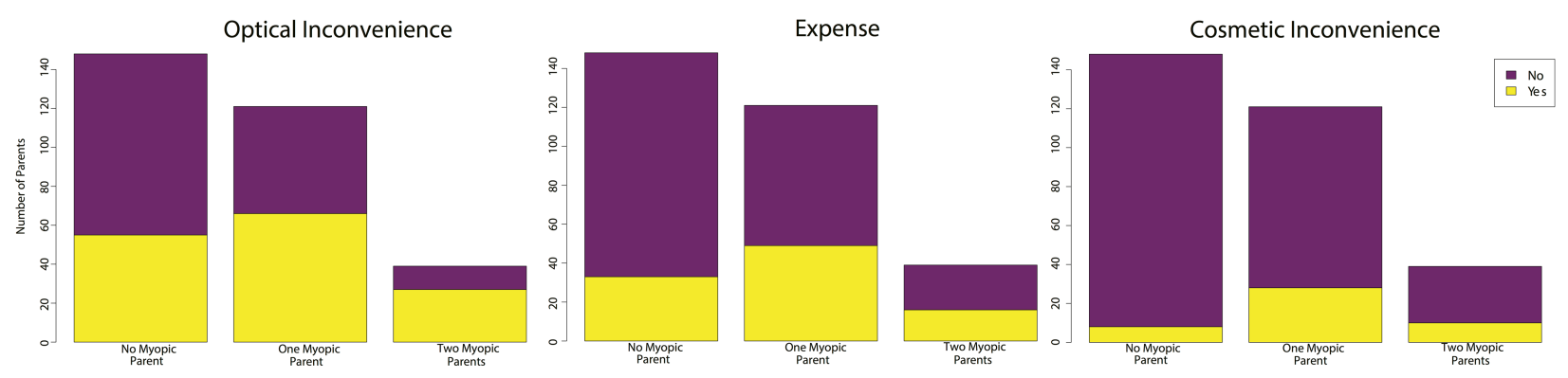

Figure 5 Relationship between attitudes and family myopia status for Optical Inconvenience (left), Expense (middle) and Cosmetic Inconvenience (right).

A chi-square test of independence confirmed there was no significant difference in attitudes toward myopia between urban and rural parents (optical inconvenience $P=0.46$, cosmetic inconvenience $P=0.27$, expense $P=0.08$, intelligence $P=0.33$, health Risk $P=0.41$ ).

\section{Daily Activities of Children}

Parents recorded their children as spending twice as much time on digital devices on weekend days compared to weekdays. Children spent a daily total of 255 minutes on average participating in proximal tasks at home and in school, equating to $41 \%$ more time spent on proximal tasks relative to outdoors. Parental assessment of their children's activities is represented in Table 2. 
Table 2: Parental diary recordings (median and confidence intervals) of the daily time (mins) for older vs. younger children, urban vs. rural based children and myopic vs. non myopic children

\begin{tabular}{|c|c|c|c|c|c|c|c|c|c|}
\hline & \multicolumn{3}{|c|}{ Age } & \multicolumn{3}{|c|}{ Location } & \multicolumn{3}{|c|}{$\begin{array}{c}\text { Refractive } \\
\text { Status }\end{array}$} \\
\hline & $\begin{array}{l}8-10 \\
\text { years }\end{array}$ & $\begin{array}{l}11-13 \\
\text { years }\end{array}$ & $P^{*}$ & Urban & Rural & $P^{*}$ & Myopes & $\begin{array}{l}\text { Non } \\
\text { Myopes }\end{array}$ & $P^{*}$ \\
\hline $\begin{array}{l}\text { Proximal } \\
\text { Indoor } \\
\text { activities }\end{array}$ & $\begin{array}{l}231 \text { mins } \\
(127,334)\end{array}$ & $\begin{array}{l}278 m i n s \\
(165,411)\end{array}$ & $=0.01$ & $\begin{array}{l}270 \text { mins } \\
(154,392)\end{array}$ & $\begin{array}{l}240 \text { mins } \\
(139,361)\end{array}$ & $=0.01$ & $\begin{array}{l}341 \text { mins } \\
(233,429)\end{array}$ & $\begin{array}{l}244 \text { mins } \\
(142,368)\end{array}$ & $=0.02$ \\
\hline Screens & $\begin{array}{l}77 \text { mins } \\
(52,137)\end{array}$ & $\begin{array}{l}\text { 111mins } \\
(73,186)\end{array}$ & $=0.001$ & $\begin{array}{l}99 \mathrm{mins} \\
(74,172)\end{array}$ & $\begin{array}{l}77 \text { mins } \\
(47,154)\end{array}$ & $=0.0005$ & $\begin{array}{l}135 \mathrm{mins} \\
(78,196)\end{array}$ & $\begin{array}{l}90 \text { mins } \\
(60,158)\end{array}$ & $=0.04$ \\
\hline Outdoors & $\begin{array}{l}180 \text { mins } \\
(134,246)\end{array}$ & $\begin{array}{l}180 \text { mins } \\
(120,266)\end{array}$ & $=0.76$ & $\begin{array}{l}166 m i n s \\
(124,249)\end{array}$ & $\begin{array}{l}193 m i n s \\
(139,261)\end{array}$ & $=0.05$ & $\begin{array}{l}177 \text { mins } \\
(103,129)\end{array}$ & $\begin{array}{l}193 \text { mins } \\
(139,261)\end{array}$ & $=0.17$ \\
\hline
\end{tabular}

*Three-way ANOVA analysis, $\mathrm{P}$ values relate to log transformed data

\section{Proximal Indoor Activities}

A three-way ANOVA run on a sample of 287 participants revealed older $[\mathrm{F}(1,279)=6.31, \mathrm{MSE}=3.10$, $P=0.01]$, myopic children $[\mathrm{F}(1,279)=5.57, \mathrm{MSE}=2.74, P=0.02]$ from an urban area $[\mathrm{F}(1,279)=6.66$, $\mathrm{MSE}=3.27, P=0.01]$ spent significantly more time participating in proximal indoor activities compared to younger non-myopic children. There were no significant interactions.

\section{Screen time}

A three-way ANOVA on a sample of 278 participants revealed older $[\mathrm{F}(1,270)=10.80, \mathrm{MSE}=7.034, P=$ $0.001]$, myopic children $[\mathrm{F}(1,270)=3.89, \mathrm{MSE}=2.53, P=0.04]$ from an urban background $[\mathrm{F}(1,270)=$ 12.27, $\mathrm{MSE}=8.00, P<0.001]$ spent significantly more time using digital screens compared to younger non-myopic urban based children. There were no significant interactions.

\section{Outdoor Activity}

A three-way ANOVA run on a sample of 293 participants revealed no significant effect of age, $[F(1,284)$ $=0.09, \mathrm{MSE}=0.03, P=0.76]$, or refractive status $[\mathrm{F}(1,284)=1.94, \mathrm{MSE}=0.63 P=0.17]$ on the amount of outdoor activity, although location was borderline significant $[\mathrm{F}(1,284)=3.76, \mathrm{MSE}=1.21, P=0.05]$. There were no significant interactions. 
The diary responses revealed a discordance between child and parent recorded activities, with parents assigning more time to all tasks relative to children. However the findings are similar irrespective of which data are used: older, myopic children from an urban background spent less time outside, and more time participating in indoor activities and on screens compared to younger non myopes from a rural area.

\section{$\underline{\text { Discussion }}$}

This study advances our knowledge in relation to myopia, particularly in relation to parental attitudes and understanding of the condition. Parental understanding of the causes of myopia was limited. Perhaps the most salient findings to emerge from this study include the lack of recognition of the health risks for eye disease and vision loss associated with myopia and the lack of parental concern associated with a diagnosis of myopia in a child. This extends previous research which has highlighted that parents are motivated to avoid ocular damage to their child's eyes from myopia, but have a lack of information and understanding as to how this can be achieved. ${ }^{51}$, Even though the majority of parents in our study reported that they limited their child's screen-time, children spent over 14 hours per week on average at a screen. Given that the study was conducted at a time of year with plenty of opportunity for quality time to be spent outdoors, this suggests that strict limits were not enforced. Additionally, even though some parents did consider myopia as a health risk, their children's level of myopia risk exposure was no different from those of children whose parents did not consider myopia as a health risk. Given the dominant influence parents have on their child's lifestyle choices, these findings confirm that public education about myopia and its risk factors is important in order to close this critical knowledge gap and to generate a shift in the attitude and behaviours of individuals at risk of myopia. From a public health policy perspective, successful realisation of any strategy to control the development of myopia and associated disease will depend heavily on the informed participation of parents.

This study has also explored Irish children's current daily lifestyle habits for the first time, and quantified the level of exposure of different groups to driving factors associated with incident and progressive myopia. Our findings corroborate and extend previous research and demonstrate clearly that child exposure to risk factors known to influence the development of myopia are associated with increasing age, urbanisation and existing myopia.

Non-myopic children spent an additional two hours per week on average outdoors relative to myopes. This supports the results of the Avon Longitudinal Study of Parents and Children (ALSPAC) study where 
the weekly average difference was just over three hours. ${ }^{33}$ The difference in the amount of time urban based children spent outdoors relative to rural children was almost identical in this study to that identified in Guo et al.'s study, who found that primary school children from the urban region of Beijing spent an additional one hour per day outdoors compared to children in rural Beijing. ${ }^{52}$

Urbanisation is thought to be linked to increasing prevalence of myopia due to a lack of green spaces, less time outdoors and changes in lifestyle in more densely populated areas. ${ }^{53,24}$ It has been predicted that by the year $2050,75 \%$ of the Irish population and over $80 \%$ of the European population will live in urban areas. ${ }^{54,55}$ Given our finding that urban based children spend less time outdoors relative to rural children, these urbanisation trends will necessitate a comprehensive strategy to avoid a continuation and exacerbation of the observed pattern of increasing prevalence of myopia in cities compared to rural areas. ${ }^{56}$ The lack of awareness expressed by parents in this study illustrates clearly that the strategy will need to engage parents directly so they can play a prominent role in reversing the indoors to outdoors activity time balance.

Older children in our study also spent more time using visual displays than younger children. The threefold variance in mobile phone usage between older and younger children is notable. This transition is not unexpected as older children are more likely to have a phone but the young age range of our primary school participant cohort makes this considerable increase particularly interesting. The closer working distance of a mobile phone compared to a computer screen or a book places greater visual demands on the ocular system, ${ }^{57}$ which is important given that closer reading distances and continuous reading have been identified in some studies as risk factors for myopia. ${ }^{21,25}$ These findings compliment previous observations that increasing age is accompanied by a decline in time spent outdoors coupled with increased computer use. ${ }^{58,59,60,61}$ It has been reported, for example, that the average UK teen and adult spends more time using media and technology than they do sleeping. ${ }^{62}$ The continuous technological revolution and our sudden reliance on technology at home, work, in schools, our cars and in almost every aspect of our lives may be a significant factor in the sudden rise in myopia in many countries, especially among children who are becoming myopic at a younger age ${ }^{7,8}$. It could also be argued that increased use of technology and devices competes with other more protective activities such as time outdoors, ${ }^{63}$ thereby potentially exerting both a direct and indirect influence on myopia development and progression and also making it more difficult to tackle the current pandemic. ${ }^{64}$

Although our cohort of myopic children was relatively small in number $(n=45)$, they spent significantly more time indoors participating in proximal tasks and at screens compared to non-myopes. This supports 
the observation in other studies that increased amounts of close work contribute to a higher prevalence and severity of myopia. ${ }^{26,65,24}$ Saw et al. reported that among 8-9 year old children, myopes performed more total near work activities $(2.7 \pm 0.7 \mathrm{hrs} /$ day $)$ than non-myopes $(2.3 \pm 1 \mathrm{hrs} /$ day $)$ daily $(\mathrm{p}=0.0027){ }^{56}$ which mirrors our finding that myopic children spent an additional 20 minutes per day on proximal screens compared to non myopes.

The primary approach to myopia management in children currently prioritises the alleviation of its defining symptom of blurred distance vision. Practitioners, patients and parents generally consider the condition effectively managed through the simple correction of the refractive error, typically using spectacles. The essentially universal parental acceptance of this simple and convenient corrective device means that compliance with the treatment is high, even in young children, and the symptoms of myopia are therefore very successfully managed. ${ }^{66}$ Perhaps of more importance is the lack of any significant burden on parents associated with this form of treatment, beyond of course, the occasional need for reminders to wear the spectacles, repair or replacement of broken spectacles and return for future eye examinations. The interventions required to prevent and control the spread of myopia are likely to be substantially more burdensome to parents. Convincing children to give up their smartphone in favour of outdoors activities might not be easy. There will also be added costs to parents, both in terms of time and finances. Optical and pharmacologic interventions will require investment above and beyond the usual costs of spectacles (which will still be required). The burden of care will also increase, requiring more eye care visits, more time to adopt the intervention (e.g. insert eye drops or contact lenses), to manage any complications that arise and to manage any child acceptance issues. The critical role of parents in the acceptance and efficacy of such new treatments is evidenced in other existing public health domains such as, for example the low uptake on the HPV vaccination due to parental resistance from misrepresentation of the benefits of the vaccine. ${ }^{67}$ Therefore, the arguments in favour of myopia control will need to be comprehensively and clearly made to parents and children alike to ensure the strategies are broadly accepted and successfully implemented.

\section{$\underline{\text { Limitations }}$}

Time spent participating in daily activities was self-reported by participants at the end of each day. The diary responses revealed a discordance between child and parent recorded activities, with parents assigning statistically significantly more time to all tasks relative to children. The accuracy of this approach is difficult to gauge but is likely to provide a better estimate than a general questionnaire 
approach. The fact that the statistical conclusions are identical, however, irrespective of whether child or adult diary entries are used, provides reassurance as to the robustness of our findings.

It must be taken into consideration that time spent participating in activities such as reading and outdoors will depend on weather, hours of daylight and school holidays. Our study was conducted in May when there is an average of 16 hours daylight in Dublin, Ireland, compared to less than eight hours in December. ${ }^{68}$ Thus even though children were participating in proximal school and homework tasks in the current study, as it was a warmer summer month at the end of the school year, it was more likely that children spent an increased amount of time outdoors on the week they recorded their dairies, compared to if the study was carried out over winter months. ${ }^{69}$ This study also recorded children's daily activities for one week only. A study stretching over a longer time span or a corresponding study completed at several time points across the year including winter time and during school holidays would be advantageous, as time spent participating in various activities will likely vary depending on weather, daylight hours and the academic calendar. Parental attitudes, however, are unlikely to have been affected by such seasonal factors. The attitudes of other stakeholders such as children themselves, teachers and clinicians were not explored herein, but are also important in considering future myopia control strategies.

All children participating in the study were under 13 years of age. Further investigation into the daily activities of older students would establish if progression into older childhood further increases exposure to myopia risk factors at a time when parental influence can become less significant, ${ }^{70}$ as one would anticipate that teenagers might spend more time engaged in indoors proximal tasks, particularly in the use of electronic displays for social media.

Study participation rate was $30 \%$, which we consider an acceptable survey response rate. Numerous studies have highlighted the difficultly in achieving high participation rates in school based studies. ${ }^{71,72,73}$. Reasons for lower participation may include the young age cohort of children and their lack of understanding of the task as well as the importance of the study, non consent from parents (in which case they most likely did not return the questionnaire and consent form to the school), a lack of direct contact and engagement with parents and a lack of repeat follow up reminders and visits to schools to collect completed diaries and questionnaires. 
One concern of potential bias was whether myopic parents would be more motivated to participate and complete our study. $30 \%$ of parents in our study were myopic, which is comparable to the prevalence of myopia in 30-59 year old adults (36\%) in the $\mathrm{E}^{3}$ Consortium, ${ }^{74}$ suggesting that selection bias is not a significant concern.

\section{Conclusion}

Parental attitudes to myopia were typically nonchalant in relation to health risk. The role of parents in the acceptance of any interventional treatments, either pharmacological or optical, needs to be recognised. The knowledge gap identified amongst parents in this study will need to be addressed as part of the process of implementation of any therapies for myopia progression. Parents' views of the dominant risk factors for myopia were also at odds with the literature. This is of particular concern given the impact parents have on children's behaviour and choices with respect to such risk factors, demonstrating an acute need for societal sensitisation to the public health importance of myopia. 


\section{$\underline{\text { References }}$}

1. Morgan IG, Ohno-Matsui K \& Saw S-M. Myopia. The Lancet 2012; 379(9827): 1739-48

2. Holden BA, Fricke TR, Wilson DA et al. Global Prevalence of Myopia and High Myopia and Temporal Trends from 2000 through 2050. Ophthalmology 2016; 123(5):1036-42.

3. Pan C-W, Ramamurthy D \& Saw S-M. Worldwide prevalence and risk factors for myopia. Ophthalmic Physiol Opt 2012; 32(1): 3-16.

4. Vitale S, Sperduto RD \& Ferris FL. Increased prevalence of myopia in the United States between 1971-1972 and 1999-2004. Arch Ophthalmol. 2009; 127(12): 1632-1639

5. Wolfram C, Höhn R, Kottler U et al. Prevalence of refractive errors in the European adult population: the Gutenberg Health Study (GHS). Br J Ophthalmol 2014; 98: 857-61.

6. Logan NS, Davies LN, Mallen EAH et al. Ametropia and ocular biometry in a U.K. university student population. Optom Vis Sci 2005; 82(4): 261-6.

7. Lin LLK, Shih YF, Hsiao CK \& Chen CJ. Prevalence of myopia in Taiwanese schoolchildren: 1983 to 2000. Ann Acad Med Singapore 2004 Jan; 33(1): 27-33.

8. McCullough SJ, O’Donoghue L \& Saunders KJ. Six Year Refractive Change among White Children and Young Adults: Evidence for Significant Increase in Myopia among White UK Children. PLoS One 2016; 11(1): e0146332.

9. Foster PJ \& Jiang Y. Epidemiology of myopia. Eye (Lond) 2014; 28(2): 202-8.

10. Saw S-M, Gazzard G, Shih-Yen EC \& Chua WH. Myopia and associated pathological complications. Ophthalmic Physiol Opt 2005; 25(5): 381-91.

11. Flitcroft DI. The complex interactions of retinal, optical and environmental factors in myopia aetiology. Prog Retin Eye Res. 2012; 31(6): 622-660.

12. Hayashi K, Ohno-Matsui K, Shimada N et al. Long-term Pattern of Progression of Myopic Maculopathy. Ophthalmology 2010; 117(8): 1595-1611.e4.

14. Holden B, Sankaridurg P, Smith E, Aller T, Jong M \& He M. Myopia, an underrated global challenge to vision: where the current data takes us on myopia control. Eye 2013 ; 28: 142-6.

15. Evans JR, Fletcher AE \& Wormald RPL. Causes of visual impairment in people aged 75 years and older in Britain: an add-on study to the MRC Trial of Assessment and Management of Older 
People in the Community. Br J Ophthalmol 2004; 88(3): 365-70.

16. Kelliher C, Kenny D \& O'Brien C. Trends in blind registration in the adult population of the Republic of Ireland 1996-2003. Br J Ophthalmol 2006; 90(3): 367-71.

17. Cedrone C, Nucci C, Scuderi G, Ricci F, Cerulli A \& Culasso F. Prevalence of blindness and low vision in an Italian population: a comparison with other European studies. Eye (Lond) 2006; 20(6): 661-7.

18. Buch H, Vinding T, La Cour M, Appleyard M, Jensen GB \& Nielsen NV. Prevalence and causes of visual impairment and blindness among 9980 Scandinavian adults: the Copenhagen City Eye Study. Ophthalmology 2004; 111(1): 53-61.

19. Klaver CC, Wolfs RC, Vingerling JR, Hofman A \& de Jong PT. Age-specific prevalence and causes of blindness and visual impairment in an older population: the Rotterdam Study. Arch Ophthalmol 1998;116(5): 653-8.

20. Morgan RW, Speakman JS \& Grimshaw SE. Inuit myopia: an environmentally induced “epidemic.” Can Med Assoc J. 1975; 112(5): 575-577.

21. Flitcroft DI. Ophthalmologists should consider the causes of myopia and not simply treat its consequences. Br J Ophthalmol 1998; 82(3): 210-1.

22. Young FA, Leary GA, Baldwin WR et al. The transmission of refractive errors within eskimo families. Am J Optom Arch Am Acad Optom 1969; 46(9): 676-85.

23. Zylbermann R, Landau D \& Berson D. The influence of study habits on myopia in Jewish teenagers. J Pediatr Ophthalmol Strabismus 1993; 30(5): 319-22.

24. Ip JM, Saw S-M, Rose KA et al. Role of near work in myopia: findings in a sample of Australian school children. Invest Ophthalmol Vis Sci. 2008; 49(7): 2903-10.

25. Huang H-M, Chang DS-T \& Wu P-C. The Association between Near Work Activities and Myopia in Children? A Systematic Review and Meta-Analysis. Jhanji V, editor. PLoS One 2015; 10(10): e0140419.

26. Saw S, Chua W, Hong C et al. Nearwork in Early-Onset Myopia. Invest Ophthalmol Vis Sci. 2002; 43(2): 332-9

27. Fernández-Montero A, Olmo-Jimenez JM, Olmo N et al. The impact of computer use in myopia progression: A cohort study in Spain. Prev Med 2015; 71: 67-71.

28. Czepita D, Mojsa A, Ustianowska M, Czepita M \& Lachowicz E. Reading, writing, working on a computer or watching television, and myopia. Klin Oczna 2010; 112(10-12): 293-5.

29. Zhou J, Ma Y, Ma J et al. Prevalence of myopia and influencing factors among primary and middle school students in 6 provinces of China. Zhonghua Liu Xing Bing Xue Za Zhi 2016; 37(1):29-34. 
30. Meeker M. 2015 Internet Trends - Kleiner Perkins Caufield Byers, http://www.kpcb.com/blog/2015-internet-trends, accessed 12/04/17

31. Escobar-Chaves SL \& Anderson CA. Media and risky behaviors. Future Child 2008; 18(1): 14780 .

32. Xiong S, Sankaridurg P, Naduvilath $\mathrm{T}$ et al. Time spent in outdoor activities in relation to myopia prevention and control : a meta-analysis and systematic review. Acta Ophthalmol 2017; 95(6): 551-566

33. Guggenheim JA, Northstone K, McMahon G et al. Time Outdoors and Physical Activity as Predictors of Incident Myopia in Childhood: A Prospective Cohort Study. Investig Opthalmology Vis Sci 2012; 53(6): 2856-65.

34. Jones LA, Sinnott LT, Mutti DO, Mitchell GL, Moeschberger ML \& Zadnik K. Parental History of Myopia, Sports and Outdoor Activities, and Future Myopia. Investig Opthalmology Vis Sci 2007; 48(8):3524-32.

35. Rose KA, Morgan IG, Ip J et al. Outdoor Activity Reduces the Prevalence of Myopia in Children. Ophthalmology 2008; 115(8): 1279-85.

36. Williams KM, Bertelsen G, Cumberland P et al. Increasing Prevalence of Myopia in Europe and the Impact of Education. Ophthalmology $2015 \mathrm{Jul} ; 122(7): 1489-97$

37. Lenhart A, Duggan M, Analyst R et al. Teen, Social Media and Technology Overview 2015, www.pewresearch.org, accessed 12/0, accessed 12/04/17

38. He M, Xiang F, Zeng Y et al. Effect of Time Spent Outdoors at School on the Development of Myopia Among Children in China. JAMA 2015; 314(11): 1142-8

39. Wu P-C, Tsai C-L, Wu H-L et al. Outdoor Activity during Class Recess Reduces Myopia Onset and Progression in School Children. Ophthalmology 2013; 120(5): 1080-5.

40. Huang J, Wen D, Wang Q et al. Efficacy Comparison of 16 Interventions for Myopia Control in Children. Ophthalmology 2016; 123(4): 697-708.

41. Wolffsohn JS, Calossi A, Cho P et al. Global trends in myopia management attitudes and strategies in clinical practice. Contact Lens Anterior Eye. 2016; 39(2):106-16.

42. Ganesan P \& Wildsoet CF. Pharmaceutical intervention for myopia control. Expert Rev Ophthalmol 2010; 5(6): 759-87.

43. American Optometric Association: Computer Vision Syndrome Threatens Returning Students -Occupational Health \&amp; Safety, https://ohsonline.com/Articles/2007/08/AmericanOptometric-Association-Computer-Vision-Syndrome-Threatens-Returning-Students.aspx, accessed 11/05/17 
44. Li L, Lam J, Lu Y et al. Attitudes of students, parents, and teachers toward glasses use in rural China. Arch Ophthalmol 2010; 128(6): 759-65.

45. Zühlke LJ \& Engel ME. The Importance of Awareness and Education in Prevention and Control of RHD. Glob Heart 2013; 8: 235-9.

46. Lindsay AC, Sussner KM, Kim J \& Gortmaker S. The role of parents in preventing childhood obesity. Future Child 2006; 16(1): 169-86.

47. Golan M. Parents as agents of change in childhood obesity--from research to practice. Int J Pediatr Obes 2006; 1(2): 66-76.

48. Ash T, Agaronov A, Young T, Aftosmes-Tobio A \& Davison KK. Family-based childhood obesity prevention interventions: a systematic review and quantitative content analysis. Int $\mathrm{J}$ Behav Nutr Phys Act 2017; 14(1): 113.

49. Lwin MO \& Saw S-M. Protecting children from myopia: a PMT perspective for improving health marketing communications. J Health Commun. 2007; 12(3): 251-68.

50. Range L, Embry T \& MacLeod T. Active and passive consent: a comparison of actual research with children. Ethical Hum Sci Serv 2001; 3(1): 23-31.

51. Li L, Lam J, Lu Y et al. Attitudes of Students, Parents, and Teachers Toward Glasses Use in Rural China. Arch Ophthalmol 2010; 128(6): 759.

52. Guo Y, Liu LJ, Xu L et al. Outdoor activity and myopia among primary students in rural and urban regions of Beijing. Ophthalmology. 2013; 120(2): 277-83.

53. Lee YY, Lo CT, Sheu SJ, \& Lin JL. What Factors are Associated with Myopia in Young Adults? A Survey Study in Taiwan Military Conscripts. Investig Opthalmology Vis Sci 2013; 54(2): 1026.

54. Country Profiles, https://esa.un.org/unpd/wup/Country-Profiles/, accessed 30/06/17

55. BBVA Research. European Urbanization Trends, https://www.bbvaresearch.com/en/publicaciones/european-urbanization-trends/, accessed 23/10/17

56. Saw SM, Hong RZ, Zhang MZ et al. Near-Work Activity and Myopia in Rural and Urban Schoolchildren in China. J Pediatr Ophthalmol Strabismus 2001 May 1; 38(3): 149-55.

57. Bababekova Y, Rosenfield M, Hue JE \& Huang RR. Font size and viewing distance of handheld smart phones. Optom Vis Sci. 2011; 88(7): 795-7.

58. Cleland V, Timperio A, Salmon J, Hume C, Baur LA \& Crawford D. Predictors of time spent outdoors among children: 5-year longitudinal findings. J Epidemiol Community Health. 2010 May; 64(5): 400-6

59. Sallis JF. Age-related decline in physical activity: a synthesis of human and animal studies. Med Sci Sports Exerc 2000; 32(9): 1598-600. 
60. De Jong E, Visscher TLS, HiraSing RA, Heymans MW, Seidell JC \& Renders CM. Association between TV viewing, computer use and overweight, determinants and competing activities of screen time in 4- to 13-year-old children. Int J Obes 2013; 37(1): 47-53.

61. Klesges LM, Baranowski T, Beech B et al. Social desirability bias in self-reported dietary, physical activity and weight concerns measures in 8- to 10-year-old African-American girls: results from the Girls health Enrichment Multisite Studies (GEMS). Prev Med 2004; 38(2): 78-87.

62. Ofcom. The Communications Market Report 2014, https://www.ofcom.org.uk/_data/assets/pdf_file/0031/19498/2014_uk_cmr.pdf, accessed $13 / 04 / 17$

63. French AN, Ashby RS, Morgan IG \& Rose KA. Time outdoors and the prevention of myopia. Exp Eye Res. 2013; 114: 58-68.

64. Rose KA, French AN \& Morgan IG. Environmental Factors and Myopia. Asia-Pacific J Ophthalmol 2016; 5(6): 403-10.

65. Khader YS, Batayha WQ, Abdul-Aziz SMI \& Al-Shiekh-Khalil MI. Prevalence and risk indicators of myopia among schoolchildren in Amman, Jordan. East Mediterr Health J. 2006 May-Jul;12(34):434-9.

66. Horwood AM. Compliance with first time spectacle wear in children under eight years of age. Eye 1998; 12(2): 173-8.

67. Perkins RB \& Clark JA. Providers' Perceptions of Parental Concerns about HPV Vaccination. J Health Care Poor Underserved 2013; 24(2):828-39.

68. Timebie. Sunrise Sunset Daylight Hours of Dublin, Ireland, http://www.timebie.com/sun/dublinie.php, accessed 12/04/17

69. Cooper AR, Page AS, Wheeler BW, Hillsdon M, Griew P \& Jago R.Patterns of GPS measured time outdoors after school and objective physical activity in English children: the PEACH project. Int J Behav Nutr Phys Act 2010; 7(1): 31.

70. Adeniyi OA \& Adio MO. Adolescence-Parent Relationship as a Correlates of Academic Performance on Agricultural Science in Ibadan North Local Government Area. Int J Sci Res ISSN 2012; 3(9): 2319-7064.

71. Schilpzand EJ, Sciberras E, Efron D, Anderson V \& Nicolson JM.Improving survey response rates from parents in school-based research using a multi-level approach. PLoS One 2015; 10(5): e0126950.

72. Vukotich CJ, Cousins J \& Stebbins S. Building Sustainable Research Engagements: Lessons Learned From Research With Schools. J Res Pract 2014; 10: 1-18

73. Midford R, McBride N \& Farrington F. Conducting research in schools: lessons learnt from 
experience. Heal Promot J Aust Off J Aust Assoc Heal Promot Prof 2000; 10(1): 63-8.

74. Williams KM, Verhoeven VJM, Cumberland P et al. Prevalence of refractive error in Europe: the European Eye Epidemiology (E(3)) Consortium. Eur J Epidemiol 2015; 30(4): 305-15. 